\title{
“Fiziksel Bilimler” Konu Alanlarına Göre Türkiye'nin TIMSS 2011 Dördüncü Sınıf Fen Sorularının Değerlendirilmesi
}

\author{
Gonca ÇAKMAK ${ }^{1}$ \\ 1 Arş. Gör. Dr., Dicle üniversitesi Ziya Gökalp Eğitim Fakültesi Fen Bilgisi Eğitimi A:B:D, goncacakmak08@gmail.com
}

DOI: http://dx.doi.org/10.14582/DUZGEF.1903

ÖZ

Bu çalışmanın amacı, TIMSS 2011' de yayımlanan Türkiye'nin başarılı ve başarısız olduğu dördüncü sınıf fen sorularının "Fiziksel Bilimler" konu alanlarına göre değerlendirmektir. Betimsel bir araştırma olan bu çalışmanın veri toplama aracı TIMSS 2011 ülke verileridir. Veriler betimsel istatistik teknikleri kullanılarak analiz edilmiştir. Çalısmada TIMSS 2011'de yayımlanan Türkiye'nin başarılı olduğu dördüncü sınıf fen sorularından en fazla başarılı olunan "Fiziksel Bilimler" konu alanının "Maddenin Özellikleri ve Sınıflandırılması"; TIMSS 2011'de yayımlanan Türkiye’nin bașarısız olduğu dördüncü sınıf fen sorularından en fazla bașarısız olunan "Fiziksel Bilimler" konu alanının "Enerijinin Etkileri ve Kaynakları" olduğu sonucuna ulaşılmıştır. Türkiye'nin en başarılı ve başarısız olduğu soruların dördüncü sınıf fen ve teknoloji öğretim programında yer alan kazanımları ölçmeye yönelik olduğu tespit edilmiștir. En başarısız olunan soruyla ilgili kazanımın dördüncü sınıf fen ve teknoloji öğretim programının son ünitesinde yer aldığ belirlenmiștir.

Anahtar Kelimeler: TIMSS, Fen, Türkiye

\section{Assessment of the Fourth Grade Science Questions of Turkey in the Subject} Areas of Physical Science in TIMSS 2011

\begin{abstract}
The aim of this study is to assess Turkey's successful and unsuccessful of the fourth grade science questions which were published in the TIMSS 2011 according to the subject areas of "Physical Science". The data collection tool of this study, which is a descriptive study, is the TIMSS 2011 country's data. Fourth grade science questions published in TIMSS 2011 were analyzed by using descriptive statistics according to subject areas of "Physical Science". As a result of this study, it was found that while "Classification and Properties of Matter" was the most successful subject area; "Sources and Effects of Energy" was the most unsuccessful area in the fourth grade science questions in the subject area of "Physical Science" published in TIMSS 2011. Questions that Turkey was the most successful and unsuccessful were aimed to measure the learning outcomes of the fourth grade science and technology curriculum. It was determined that the last unit of the fourth grade science and technology curriculum was related to the learning outcome of the least successful question.
\end{abstract}

Keywords: TIMSS, Science, Turkey

\section{GİRİŞ}

Dört yılda bir Uluslararası Eğitim Başarılarını Değerlendirme Kuruluşu'nun düzenlediği tarama araştırması olan TIMSS, tasarlanan bir ölçek yardımıyla öğrencilerin matematik ve fen konu alanındaki başarı durumlarını ölçmektedir. Bu sınav sonucunda elde edilen veriler değerlendirilerek matematik ve fen konu alanında öğretim ve öğrenim faaliyetlerinin okullarda nasıl gerçekleştiği tespit edilmektedir. TIMSS sınavları, dünya çapında ülkelerin eğitim sistemleri arasındaki farkllıkları ölçmekte ve değerlendirmektedir. Öğrencilerin matematik ve fen alanlarındaki performanslarını ölçmekle birlikte, bu sınavla öğrenci, öğretmen ve okulların 
özellikleri yanında eğitim sistemleri ve öğretim programları ile ilgili veriler de toplanmaktadır (Büyüköztürk, Çakan, Tan \& Atar, 2014). Bu açıklamalar doğrultusunda Türkiye'nin katıldı̆̆ı TIMSS sınavlarındaki gelişimin incelenmesi araştırmacıların kendi eğitim sistemlerinin işleyişlerini daha iyi anlayabilmeleri açısından büyük önem arz etmektedir (Çakmak, 2016; Çakmak, 2017a; Çakmak, 2017b; Çakmak, 2018a; Çakmak, 2018b; Güzel \& Çakmak, 2017).

Kimya ve fizik konu alanlarını içerisinde barındıran "Fiziksel Bilimler" konu alanı günlük yaşamda merak edilen olay ya da durumların çoğunu açıklayan TIMSS konu alanlarından biridir. Ülkemizde TIMSS sınavlarının incelendiği pek çok araştırmada (Abazaoğlu, Yıldızhan \& Yıldırım, 2014; Akyüz, 2014; Bilican, Demirtaşl1 \& Kilmen, 2011; Bütüner \& Güler, 2017; Koca \& Şen, 2002; Koğar \& Koğar, 2017; Kıllç, 2002; Öztürk \& Uçar, 2010; Uzun, Bütüner \& Yiğit, 2010; Yayan \& Berberoğlu, 2004; Yıldırım, Demirtaşlı \& Akbaş, 2012) yapılmış olup TIMSS sınavlarında sorulan fen ve matematik sorularının araştırıldığı çalışmalanın (Çakmak, 2016; Çakmak, 2017a; Çakmak, 2017b; Çakmak, 2018a; Çakmak, 2018b; Güzel \& Çakmak, 2017; Olkun \& Aydoğdu, 2003; Toluk, 2003) son derece sınırlı olduğu görülmüştür. TIMSS sınavlarında sorulan fen ve matematik sorularının değerlendirilmesiyle Türkiye'deki öğrenci başarı düzeyi daha iyi ölçülebileceği için bu gibi araştırmaların yapılması eğitim sistemlerinin gözden geçirilmesi için önemli görülmektedir (Oral \& McGivney, 2013). Bu çalışmalardan biri olan Çakmak (2017a) yaptı̆̆ araştırmada da, Türkiye'nin TIMSS 2011'de yayımlanan dördüncü sınıf fen soruları TIMSS 2011 konu alanlanına göre değerlendirilmiş ve Türkiye en fazla başarıyı "Fiziksel Bilimler" konu alanında elde ettiği tespit edilmiştir. Fiziksel bilimlerin günlük hayatta merak edilen olayların çoğunu açıklamasından ve Türkiye TIMSS 2011'de yayımlanan dördüncü sınıf fen sorularında en fazla başarıyı "Fiziksel Bilimler" konu alanında elde etmesinden dolayı, bu çalışmada "Fiziksel Bilimler” konu alanlarına göre değerlendirme yapmaya karar verilmiştir. Bu çalışmanın amacı, TIMSS 2011' de yayımlanan Türkiye'nin başarılı ve başarısız olduğu dördüncü sınıf fen sorularının "Fiziksel Bilimler" konu alanlarına göre değerlendirmektir.

\section{YÖNTEM}

Bu araştırma Türkiye'de TIMSS 2011'e katılan ögrencilerin fen testindeki başarllı ve başarısız olduğu sorular ile "Fiziksel Bilimler" konu alanları arasındaki ilişkiyi test etmeye yönelik tasarlanmış bir betimsel araştırmadır. Betimsel araştırmalar genelde verilen bir durumu aydınlatmak, standartlar doğrultusunda değerlendirmeler yapmak ve olaylar arasında olası ilişkileri ortaya çıkarmak için yürütülür. Bu tür araştırmalarda asıl amaç, incelenen durumu etraflıca tanımlamak ve açıklamaktır (Çepni, 2014).

\subsection{Kat1limcilar}

TIMSS 2011 çalışmasına Türkiye'den dördüncü sınıf düzeyinde toplam 257 okul katılmıştır. Araştırmanın çalışma grubu, TIMSS 2011 Türkiye örneklemini oluşturan 7479 öğrencidir. Çalışmaya katılan okul sayısının en fazla yer aldığı bölgenin Marmara Bölgesi (62 okul), en az yer aldığı bölgenin ise Akdeniz Bölgesi (22 okul)

olduğu belirlenmiştir. Ayrıca dördüncü sınıf düzeyinde çalışmaya katılan öğrencilerin \%48.50’sini kız öğrenciler, \%51.50’sini erkek öğrenciler oluşturmuştur (Büyüköztürk, Çakan, Tan \& Atar, 2014).

\subsection{Verilerin Analizi}

Araştırmada, Uluslararası Eğitim Başarılarını Değerlendirme Kuruluşu'nun TIMSS 2011'e katılan öğrencilere uygulamış olduğu fen testine verilen cevaplar, veri olarak kullanılmıştır. TIMSS \& PIRLS internet sitesinden elde edilen verilerden, TIMSS 2011'de yayımlanan her bir soru maddesi için uluslararası ortalama başarı yüzdesi, Türkiye’nin ortalama başarı yüzdesi, uluslararası ortalama standart hata ve Türkiye'nin ortalama standart hatası hesaplanmıştır. Böylelikle, Türkiye'nin başarılı ve başarısız olduğu TIMSS 2011'de yayımlanan soru maddeleri bulunmuştur. Betimsel istatistik teknikleri kullanılarak (frekans, yüzde) TIMSS 2011'de yayımlanan dördüncü sınıf fen sorularının, "Fiziksel Bilimler" konu alanlarına göre değerlendirilmesi yapılmıstır.

\section{BULGULAR}


TIMSS 2011'de yayımlanan dördüncü sınıf fen sorularının, “Fiziksel Bilimler” konu alanlarına göre değerlendirmesi Tablo 1'de verilmiştir.

Tablo 1. TIMSS 2011'de yayımlanan dördüncü sınıf fen sorularının "Fiziksel Bilimler" konu alanlarına göre değerlendirmesi

\begin{tabular}{lll}
\hline Konu Alanı & Soru & $\mathbf{\%}$ \\
\hline Enerjinin Etkileri ve Kaynakları & 16 & 52 \\
Maddenin Özellikleri ve Sinıflandırılması & 11 & 35 \\
Kuvvet ve Hareket & 4 & 13 \\
Toplam & 31 & 100 \\
\hline
\end{tabular}

“Fiziksel Bilimler" konu alanlarıly ilgili TIMSS 2011'de yayımlanan dördüncü sınıf 31 fen sorusunun, \%52'si “Enerjinin Etkileri ve Kaynakları" konu alanına ait sorulardan, \%35’i "Maddenin Özellikleri ve Sınıflandırılması", \%13’ü "Kuvvet ve Hareket” konu alanına ait sorulardan oluşmuştur. TIMSS 2011'de yayımlanan dördüncü sınıf fen sorularından en fazla soru sorulan "Fiziksel Bilimler" konu alanının "Enerjinin Etkileri ve Kaynakları", en az soru sorulan konu alanının "Kuvvet ve Hareket” olduğu görülmüştür. Tablo 2'de TIMSS 2011'de yayımlanan Türkiye'nin başarılı olduğu dördüncü sınıf fen sorularının, "Fiziksel Bilimler" konu alanlarına göre değerlendirilmesinden elde edilen bulgulara yer verilmiştir.

Tablo 2. TIMSS 2011'de yayımlanan Türkiye'nin başarılı olduğu dördüncü sınıf fen sorularının "Fiziksel Bilimler" konu alanlarına göre değerlendirmesi

\begin{tabular}{lll}
\hline Konu Alanı & Soru & $\mathbf{\%}$ \\
\hline Enerjinin Etkileri ve Kaynakları & 2 & 6.50 \\
Maddenin Özellikleri ve Sinıflandırılması & 4 & 12.70 \\
Kuvvet ve Hareket & 1 & 3.20 \\
Toplam & 7 & 22.40 \\
\hline
\end{tabular}

“Fiziksel Bilimler” konu alanlarıyla ilgili TIMSS 2011'de yayımlanan Türkiye’nin başarılı olduğu dördüncü sınıf fen sorularının \%6.50'si “Enerjinin Etkileri ve Kaynakları” konu alanına ait sorulardan, \%12.70’i “Maddenin Özellikleri ve Sınıflandırılması" ve \%3.20'si “Kuvvet ve Hareket” konu alanına ait sorulardan oluşmuştur ( $\mathrm{z}>2.56)$. TIMSS 2011'e katılan Türkiye'deki öğrencilerin "Maddenin Özellikleri ve Sınıflandırılması" konu alanına ait sorularda daha fazla başarılı olduğu, "Kuvvet ve Hareket" konu alanına ait sorularda ise daha az başarılı olduğu belirlenmiştir. Böylelikle, TIMSS 2011'de yayımlanan Türkiye'nin başarllı olduğu dördüncü sınıf fen sorularından en fazla başarılı olduğu "Fiziksel Bilimler" konu alanının "Maddenin Özellikleri ve Sınıflandırılması", en az başarılı olduğu "Fiziksel Bilimler" konu alanının "Kuvvet ve Hareket" olduğu görülmüştür. Tablo 3’te Türkiye'nin başarılı olduğu "Fiziksel Bilimler" konu alanlarına ait soruların istatistiklerinden elde edilen bulgulara yer verilmiştir.

Tablo 3. Türkiye'nin başarılı olduğu "Fiziksel Bilimler" konu alanlarına ait soruların istatistikleri

\begin{tabular}{lllllc}
\hline & \multicolumn{3}{c}{ Uluslararas1 } & \multicolumn{3}{c}{ Türkiye } & Z \\
\cline { 2 - 5 } Soru Kodu & $\mathbf{\%}$ & SE & $\mathbf{\%}$ & SE & 4.45 \\
S051074 & 27 & .30 & 36 & 2.00 & 9.31 \\
S031298 & 34 & .30 & 51 & 1.80 & 3.11 \\
S041049 & 47 & .30 & 53 & 1.90 & 16.76 \\
S031410 & 64 & .30 & 88 & 1.40 & 6.37 \\
S031421 & 61 & .30 & 72 & 1.70 & 3.95 \\
S031204 & 37 & .30 & 45 & 2.00 & 3.88 \\
S031311 & 61 & .30 & 70 & 2.30 & \\
\hline
\end{tabular}

TIMSS 2011'de yayımlanan dördüncü sınıf fen sorularından "Fiziksel Bilimler" konu alanlarına ilişkin sorulan yedi soruda, Türkiye başarılı olmuştur ( $\mathrm{z}>2.56$ ). "Fiziksel Bilimler" konu alanlarıyla ilgili S051074 ve S031298 kodlu sorular “Enerjinin Etkileri ve Kaynakları”; S031311 kodlu soru “Kuvvet ve Hareket”; S041049, S031410, S031421 ve S031204 kodlu sorular ise "Maddenin Özellikleri ve Sınıflandırılması" konu alanıyla ilgilidir. "Maddenin Özellikleri ve Sınıflandırılması" konu alanıyla ilgili S031410 kodlu soruda Türkiye en yüksek z puanına sahiptir. Türkiye’nin başarılı olduğu "Maddenin Özellikleri ve Sınıflandırılması” konu alanına ait sorulardan, en yüksek z puanına ait soru Şekil 1'de yer verilmiştir. 


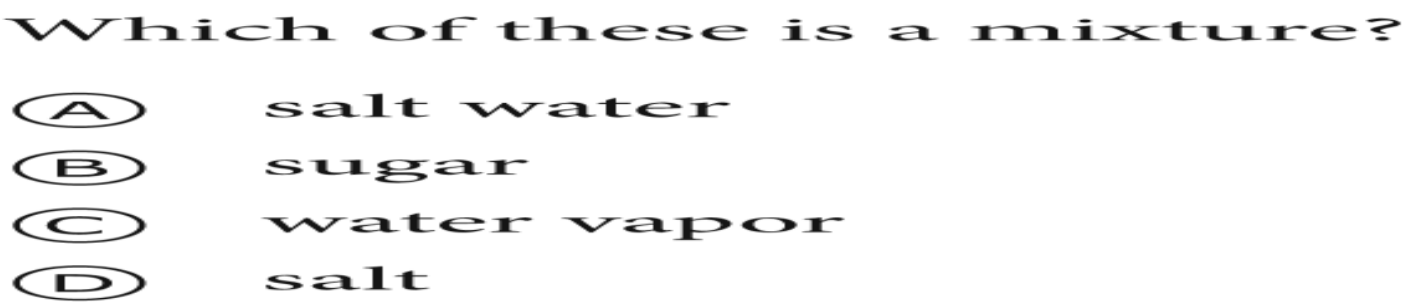

Şekil 1. S031410 kodlu soru (TIMSS\&PIRLS International Study Center, 2013)

“Maddenin Özellikleri ve Sinıflandırılması" konu alanıyla ilgili S031410 kodlu soru, MEB 2005 dördüncü sınıf öğretim programında yer alan "Bildiği saf ve karışık maddeleri listeler.” kazanımı ile ilgili sorudur. Bu soruda bir karışım örneği olan tuzlu su sorulmaktadır. Soruların bilişsel düzeyleri dikkate alındığında çoktan seçmeli olan bu sorunun "Bilme” bilişsel düzeyinde bir soru olduğu görülmektedir (Büyüköztürk, Çakan, Tan \& Atar, 2014). Tablo 4'de TIMSS 2011'de yayımlanan Türkiye'nin başarısız olduğu dördüncü sınıf fen sorularının, "Fiziksel Bilimler" konu alanlarına göre değerlendirilmesinden elde edilen bulgulara yer verilmiştir.

Tablo 4. TIMSS 2011'de yayımlanan Türkiye'nin başarısız olduğu dördüncü sınıf fen sorularının “Fiziksel Bilimler” konu alanlarına göre değerlendirmesi

\begin{tabular}{lll}
\hline Konu Alanı & Soru & $\mathbf{0}$ \\
\hline Enerjinin Etkileri ve Kaynakları & 9 & 29.20 \\
Maddenin Özellikleri ve Sinıflandırılması & 4 & 12.70 \\
Kuvvet ve Hareket & 2 & 6.50 \\
Toplam & 15 & 48.40 \\
\hline
\end{tabular}

“Fiziksel Bilimler" konu alanlarıyla ilgili TIMSS 2011'de yayımlanan Türkiye'nin başarısız olduğu dördüncü sınıf fen sorularının \%29.20'si "Enerjinin Etkileri ve Kaynakları" konu alanına ait sorulardan, \%12.70’i “Maddenin Özellikleri ve Sınıflandırılması" ve \%6.50’si “Kuvvet ve Hareket” konu alanına ait sorulardan oluşmuştur ( $\mathrm{z}<-2.56)$. TIMSS 2011’e katılan Türkiye'deki öğrencilerin "Enerjinin Etkileri ve Kaynakları" konu alanına ait sorularda daha fazla başarısız olduğu, "Kuvvet ve Hareket" konu alanına ait sorularda ise daha az başarısız olduğu belirlenmiştir. Böylelikle, TIMSS 2011'de yayımlanan Türkiye'nin başarısız olduğu dördüncü sınıf fen sorularından en fazla başarısız olduğu "Fiziksel Bilimler" konu alanının "Enerjinin Etkileri ve Kaynakları", en az başarısız olduğu "Fiziksel Bilimler" konu alanının "Kuvvet ve Hareket” olduğu görülmüştür. Tablo 5'te Türkiye'nin başarısız olduğu "Fiziksel Bilimler" konu alanlarına ait soruların istatistiklerinden elde edilen bulgulara yer verilmiştir.

Tablo 5. Türkiye'nin başarısız olduğu "Fiziksel Bilimler" konu alanlarına ait soruların istatistikleri

\begin{tabular}{llllll}
\hline & \multicolumn{3}{c}{ Uluslararas1 } & \multicolumn{3}{c}{ Türkiye } & \multirow{2}{*}{ Z } \\
\cline { 2 - 5 } Soru Kodu & $\mathbf{\%}$ & SE & $\mathbf{\%}$ & SE & -21.91 \\
S031197A & 70 & .30 & 30 & 1.80 & -20.82 \\
S031197B & 63 & .30 & 25 & 1.80 & -20.27 \\
S031197Z & 57 & .30 & 20 & 1.80 & -21.90 \\
S031197Z_1 & 75 & .30 & 35 & 1.80 & -3.92 \\
S051179 & 76 & .30 & 70 & 1.50 & -4.31 \\
S031076 & 36 & .30 & 26 & 2.30 & -6.14 \\
S041069 & 57 & .30 & 47 & 1.60 & -3.28 \\
S031273 & 56 & .30 & 50 & 1.80 & -5.22 \\
S031077 & 71 & .30 & 63 & 1.50 & -3.92 \\
S041048 & 42 & .30 & 36 & 1.50 & -2.79 \\
S041187 & .30 & 24 & 1.40 & -19.41 \\
S031371 & 28 & .30 & 40 & .20 & -14.12 \\
S031418 & 47 & .30 & 21 & 1.60 & -2.94 \\
S041117 & 44 & .20 & 87 & 1.00 & -3.83 \\
S051071 & 90 & .30 & 37 & 1.80 & \\
\hline
\end{tabular}

TIMSS 2011'de yayımlanan dördüncü sınıf fen sorularından "Fiziksel Bilimler" konu alanlarına ilişkin sorulan 15 soruda, Türkiye başarısız olmuştur ( $<<-2.56$ ). "Fiziksel Bilimler" konu alanlarıyla ilgili S031197A, S031197B, S031197Z, S031197Z-1, S051179, S031076, S041069, S031273 ve S031077 kodlu sorular "Enerjinin Etkileri ve Kaynaklar1"; S041048, S041187, S031371 ve S031418 kodlu sorular "Maddenin Özellikleri ve Sinıflandırılması"; S041117 ve S051071 kodlu sorular ise "Kuvvet ve Hareket” konu alaniyla 
ilgilidir. "Enerjinin Etkileri ve Kaynakları" konu alanıyla ilgili S031197A kodlu soruda Türkiye en düşük z puanına sahiptir. Türkiye'nin başarısız olduğu “Enerjinin Etkileri ve Kaynakları” konu alanına ait sorulardan, en düşük z puanına ait soru Şekil 2'de yer verilmiştir.

\section{Name two things electricity can be used for in daily life.}

\section{Use 1:}

Şekil 2. S031197A kodlu soru (TIMSS\&PIRLS International Study Center, 2013)

“Enerjinin Etkileri ve Kaynakları” konu alanılla ilgili S031197A kodlu soru, MEB 2005 dördüncü sınıf öğretim programında yer alan "Elektrikle çalışan araçlara örnekler verir” kazanımı ile ilgili sorudur. Bu soruda elektriğin günlük hayattaki kullanım alanları sorulmaktadır. Soruların bilişsel düzeyleri dikkate alındığında açık uçlu olan bu sorunun "Bilme” bilişsel düzeyinde bir soru olduğu görülmektedir (Büyüköztürk, Çakan, Tan \& Atar, 2014). TIMSS 2011 dördüncü sınıf fen başarı testinde üç temel bilişsel düzey olan "Bilme, Uygulama ve Akıl Yürütme” bilişsel düzeylerine odaklanılmaktadır. "Fiziksel Bilimler” konu alanlarıyla ilgili TIMSS 2011'de yayımlanan Türkiye'nin başarılı ve başarısız olduğu dördüncü sınıf fen sorularının bilişsel düzeylerinin "Bilme" olduğu tespit edilmiştir (Büyüköztürk, Çakan, Tan \& Atar, 2014).

\section{TARTIŞMA ve SONUÇ}

TIMSS 2011 araştırma sonuçlarına göre, Türkiye TIMSS ölçek orta noktasının (500 puan) altında olup dördüncü sınıf düzeyinde fen başarı ortalaması 463 puandır (Martin, Mullis, Foy \& Stanco, 2012). Türkiye'nin “Fiziksel Bilimler” konu alanlarına göre ortalama başarı puanları 466'dır (Martin, Mullis, Foy \& Stanco, 2012). Yapılan bu çalışmada TIMSS 2011'de yayımlanan Türkiye'nin başarılı olduğu dördüncü sınıf fen sorularından en fazla başarılı olunan "Fiziksel Bilimler" konu alanının "Maddenin Özellikleri ve Sınıflandırılması”; TIMSS 2011'de yayımlanan Türkiye'nin başarısız olduğu dördüncü sınıf fen sorularından en fazla başarısız olunan "Fiziksel Bilimler" konu alanının "Enerjinin Etkileri ve Kaynakları" olduğu belirlenmiştir.

Türkiye'de TIMSS 2011 soruları uygulandığı zaman yürürlükte olan öğretim program1 2005 yllına ait olduğu için bu öğretim programının incelenmesine bu çalışmada karar verilmiştir. Bu öğretim programının incelenmesi neticesinde, Türkiye'nin başarnlı ve başarısız olduğu soruların dördüncü sınıf fen ve teknoloji öğretim programında yer aldığı tespit edilmiştir. TIMSS 2011'de yayımlanan dördüncü sınıf fen sorularından Türkiye en fazla başarıyı karışım kavramıla ile ilgili soruda, en fazla başarısızlığı ise elektrik kavramı ile ilgili soruda elde etmiştir. MEB 2005 dördüncü sınıf fen ve teknoloji öğretim programında "Karışım” kavramının yer aldığı "Maddeyi Tanıyalım” ünitesi birinci dönem işlenen ikinci ünite iken, "Elektrik” kavramının yer aldığı "Yaşamımızdaki Elektrik" ünitesi ise ikinci dönem işlenen son ünite olarak öğretim programında yer almıştır. Bir ünitenin son ünite olarak öğretim programında yer almasının, öğretmenlerin öğretim programının yoğunluğundan dolayı üniteyi tam olarak işleyememelerine ve öğretmenlerin düz anlatımla üniteyi geçiştirmelerine neden olduğu düşünülmektedir. Ayrıca "Yaşamımızdaki Elektrik" ünitesinin öğretim programında son ünite olması ve havaların ısınmaya başlamasından dolayı öğrencilerin derse karşı dikkatlerini toplamada öğretmenlere problem yaşatabilmektedir. Bu durum, çevresel faktörlerin öğrenme motivasyonu üzerine olumsuz etkide bulunması ile ilişkilendirilebilir. Seven ve Engin'in (2008) yaptı̆̆ı çalışmada da benzer sonuçlar bulunmuştur. Özellikle havaların sıcak olduğu okulun kapanmasına yakın dönemlerde öğrencilerin öğrenmeye karşı daha isteksiz olduklarını, öğretmenlerin öğrencilerin dikkatlerini konuya yönlendirmede problem yaşadıklarını araştırmalarında belirtmişlerdir (Çoruhlu \& Çepni, 2015).

TIMSS 2011'de yayımlanan dördüncü sınıf fen sorularından Türkiye en fazla başarıyı çoktan seçmeli olarak hazırlanmış bir soruda, en fazla başarısızlığı ise açık uçlu olarak hazırlanmış bir soruda elde etmiştir. Bireylerin geleceğini etkileyen KPSS, LGS, YKS gibi geniş ölçekli testler sadece çoktan seçmeli maddelerden oluştuğu için öğrencilerin çoktan seçmeli soruları cevaplamaya alışkın olmaları kaçınılmazdır. Bu yüzden yapılan çeşitli sınavlarda sorulan çoktan seçmeli soruları, sınavlarda sorulan açık uçlu sorulara göre cevaplama 
oranları daha fazladır. Çakan'ın (2004) yaptığı araştırmada, öğrencileri değerlendirme amacıyla ilköğretim öğretmenlerinin çoğunluğunun çoktan seçmeli testleri kullandıkları, orta öğretim öğretmenlerinin ise açık uçlu soruları kullandıkları tespit edilmiştir. Çalışmasında ilköğretim öğretmenlerinin çoktan seçmeli soruları daha çok kullanmasının nedenlerinden biri olarak çoktan seçmeli olarak hazırlanan ortaöğretime giriş sınav1 gösterilmiştir. Benzer şekilde Gür ve Hangül'ün (2014) yaptığ1 araştırmada da öğrencilerin mevcut merkezi sınav sisteminin test tekniğine dayalı olması nedeniyle açık uçlu sorularda zaman zaman mantık yürütemedikleri düşünülmektedir.

TIMSS 2011'de yayımlanan dördüncü sınıf fen sorularından "Fiziksel Bilimler" konu alanıyla ilgili Türkiye'nin başarılı ve başarısız olduğu sorulara ilişkin kazanımlar MEB 2005 dördüncü sınıf fen ve teknoloji öğretim programında yer almaktadır. Öğretim programının uygulamasına yönelik bazı sıkıntılar bu sınıf seviyesinde başarının ve başarısızlı̆̆ın birlikte gözlenmesinin altında yatan nedenlerden biri olarak gösterilebilir. Programın uygulamasına yönelik aksaklıkları giderici önlemlerin alınması ile ilerleyen yıllarda yapılacak olan TIMSS sınavlarında, ögrencilerin daha başarılı olabileceği düşünülmektedir.

\section{KAYNAKÇA}

Abazaoğlu, İ., Yıldızhan Y. \& Yıldırım, O. (2014). TIMSS 2011 Türkiye 8. sınıf fen bilimleri sonuçlarının değerlendirilmesi. Eğitim ve Öğretim Araștrrmalar Dergisi, 3 (1), 278-288.

Akyüz, G. (2014). TIMSS 2011'de öğrenci ve okul faktörlerinin matematik başarısına etkisi. Eğitim ve Bilim, 39 (172), 150-162.

Bilican, S., Demirtaşl1, R. N. \& Kilmen, S. (2011). The attitudes and opinions of the students towards mathematics course: The comparison of TIMSS 1999 and TIMSS 2007. Kuram ve Uygulamada Ë̈itim Bilimleri, 11 (3), 1277-1283.

Bütüner S. Ö. \& Güler M. (2017). Gerçeklerle yüzleşme: Türkiye'nin TIMSS matematik başarısı üzerine bir çalışma. Bayburt Ë̆itim Fakültesi Dergisi, 12 (23), 353-376.

Büyüköztürk, S.., Çakan, M., Tan, Ş. \& Atar, H. Y. (2014). TIMSS 2011 ulusal matematik ve fen raporu: 8. sinıflar. Alınan yer http://timss.meb.gov.tr/wp-content/uploads/TIMSS-2011-8-Sinif.pdf

Çakan, M. (2004). Öğretmenlerin ölçme-değerlendirme uygulamaları ve yeterlik düzeyleri: İlk ve ortaöğretim. Ankara Üniversitesi Ĕ̈itim Bilimleri Fakültesi Dergisi, 37 (2), 99-114.

Çakmak, G. (2016). TIMSS 2007' de yayımlanan 8. sınıf fen sorularının TIMSS 2007 öğrenme alanlarına göre değerlendirilmesi: Türkiye örneği. 12. Ulusal Fen Bilimleri ve Matematik Eğitimi Kongresi Bildiri Öz̨etleri Kitabı (pp.169). Trabzon: Karadeniz Teknik Üniversitesi.

Çakmak, G. (2017a). TIMSS 2011' de yayımlanan 4. sınıf fen sorularının TIMSS 2011 konu alanlarına göre değerlendirilmesi: Türkiye örneği. 4. Uluslararası Avrasya Ĕ̆itim Bilimleri Kongresi Bildiri Özetleri Kitabı (pp.1287). Denizli: Pamukkale Üniversitesi.

Çakmak, G. (2017b). TIMSS 2011' de yayımlanan 8. sınıf fen bilimleri sorularının TIMSS 2011 konu alanlarına göre değerlendirilmesi: Türkiye örneği. Pegem Atı İndeksi, 0, 119-128.

Çakmak, G. (2018a). Türkiye'nin TIMSS 2015'de yayımlanan dördüncü sınıf fen bilimleri sorularının değerlendirilmesi. Uluslararası Bilim ve Eğgitim Kongresi Bildiri Özetleri Kitabı (pp.289). Afyon: Afyon Kocatepe Üniversitesi.

Çakmak, G. (2018b). TIMSS 2011'de yayımlanan sekizinci sınıf fen sorularının fizik konu alanına göre değerlendirilmesi: Türkiye örneği. 10. Uluslararası Eğitim Arastırmalarn Kongresi Bildiri Öz̧etleri Kitabı, (pp.173). Nevşehir: Nevşehir Hacı Bektaş Veli Üniversitesi.

Çepni, S. (2014). Araștırma ve proje çalışmalarna girişs. Trabzon: Celepler Matbaacıllık.

Çoruhlu, Ş. T. \& Çepni, S. (2015). “Güneş Sistemi ve Ötesi: Uzay Bilmecesi” ünitesinde karşılaşılan öğretmen problemleri ve yanılgıları: Bir özel durum çalısması. Kuramsal Eğitimbilim Dergisi, 8 (2), 268-281.

Gür, H. \& Hangül, T. (2015). Ortaokul öğrencilerinin problem çözme stratejileri üzerine bir çalısma. Pegem Eğgitim ve Öğretim Dergisi, 5 (1), 95-112. 
Güzel, R. \& Çakmak, G. (2017). TIMSS 2011'de yayımlanan 8. sınıf fen sorularının kimya konu alanlarına göre değerlendirilmesi: Türkiye örneği. 5. Ulusal Kimya Eğitimi Kongresi Bildiri Özetleri Kitabı (pp.31). Elazı̆̆: F1rat Üniversitesi.

Kılıç B. G. (2002). Dünyada ve Türkiye'de fen öğretimi. V. Ulusal Fen Bilimleri ve Matematik Kongresi Bildiri Özetleri Kitabı (pp.63). Ankara: Orta Doğu Teknik Üniversitesi.

Koca, A. \& Şen, İ. (2002). Evaluation of the results of third international mathematics and science study for Turkey. Hacettepe Üniversitesi Ë̆itim Fakültesi Dergisi, 23, 145-154.

Koğar H. \& Yılmaz Koğar E. (2017). Öğretmenlerin matematik konularına yönelik hazırlık düzeylerinin matematik başarısı ile ilişkisi: TIMSS 2015 Türkiye ve Singapur örneği. Başkent Üniversitesi Eğitim Fakültesi Dergisi, 2, 108-121.

Martin, M. O., Mullis, I. V. S., Foy, P. \& Stanco, G. M. (2012). TIMSS 2011 international results in science. Chestnut Hill, MA: TIMSS \& PIRLS International Study Center.

Milli Eğitim Bakanlığ1 (2005). İlkögretim fen ve teknoloji dersi (4-5-6-7-8 Simflar) ögretim programı. Ankara: Devlet Basımevi.

Olkun, S. \& Aydoğdu, T. (2003). Üçüncü uluslararası matematik ve fen araştırması (TIMSS) nedir? Neyi sorgular? Örnek geometri sorular1 ve etkinlikler. İlköğretim-Online, 2 (1), 28-35.

Oral, I. \& McGivney, E. (2013). Türkiye'de matematik ve fen bilimleri alanlannda ögrenci performansı ve başarmm belirleyicileri TIMSS 2011 analiz̨. İstanbul: Eğitim Reformu Girişimi Raporu.

Öztürk D. \& Uçar S. (2010). TIMSS verileri kullanılarak Tayvan ve Türkiye'deki 8. sınıf öğrencilerinin fen başarısına etki eden faktörlerin belirlenmesi. Cukurova Üniversitesi Sosyal Bilimler Enstitïsü Dergisi, 19, 241 256.

Seven, M. A. \& Engin, A. O. (2008). Öğrenmeyi etkileyen faktörler. Atatürk Üniversitesi Eğitim Fakültesi Dergisi, $12(2), 189-212$.

TIMSS \& PIRLS International Study Center (2013). Released items. Alinan yer http://timssandpirls.bc.edu/timss2011/international-released-items.html

Toluk, Z. (2003). Üçüncü uluslararası matematik ve fen araştırması (TIMMS): Matematik nedir? İlköğretimOnline, 2 (1), 36-41.

Uzun, S., Bütüner S. Ö. \& Yiğit, N. (2010). 1999-2007 TIMSS fen bilimleri ve matematik sonuçlarının karşılaştırılması: Sınavda en başarılı ilk beş ülke-Türkiye örneği. Elementary Education Online, 9 (3), 11741188.

Yayan, B. \& Berberoğlu, G. (2004). A re-analysis of the TIMSS 1999 mathematics assessment data of the Turkish students. Studies in Educational Evaluation, 30, 87-104.

Yıldırım, Ö., Çıkrıkçı-Demirtaşlı, N. \& Akbaş, U. (2012). The opinions of mathematics teachers on homework and in-class assessment: TIMSS 1999 and TIMSS 2007 periods. Eğitim ve Bilim, 37 (163), 126-142. 